\title{
Development and Coil Fabrication for the LARP 3.7-m Long Nb3Sn Quadrupole
}

\author{
G. Ambrosio, N. Andreev, M. Anerella, E. Barzi, R. Bossert, S. Caspi, G. Chlachidize, D. Dietderich, \\ H. Felice, P. Ferracin, A. Ghosh, R. Hafalia, R. Hannaford, G. Jochen, V.V. Kashikhin, P. Kovach, \\ M. Lamm, A. Lietzke, A. McInturff, J. Muratore, F. Nobrega, I. Novitsky, S. Peggs, S. Prestemon, \\ G.L. Sabbi, J. Schmalzle, D. Turrioni, P. Wanderer, G. Whitson, A.V. Zlobin
}

\begin{abstract}
The U.S. LHC Accelerator Research Program (LARP) has started the fabrication of 3.7-m long $\mathrm{Nb}_{3} \mathrm{Sn}$ quadrupole models. The Long Quadrupoles (LQ) are "Proof-ofPrinciple" magnets which are to demonstrate that $\mathrm{Nb}_{3} \mathrm{Sn}$ technology is mature for use in high energy particle accelerators. Their design is based on the LARP Technological Quadrupole (TQ) models, developed at FNAL and LBNL, which have design gradients higher than $200 \mathrm{~T} / \mathrm{m}$ and an aperture of $90 \mathrm{~mm}$.

The plans for the LQ R\&D and a design update are presented and discussed in this paper. The challenges of fabricating long accelerator-quality $\mathrm{Nb}_{3} \mathrm{Sn}$ coils are presented together with the solutions adopted for the LQ coils (based on the TQ experience). During the fabrication and inspection of practice coils some problems were found and corrected. The fabrication at BNL and FNAL of the set of coils for the first Long Quadrupole is in progress.
\end{abstract}

Index Terms-LARP, Long magnet, Nb3Sn, Superconducting magnet.

\section{INTRODUCTION}

$\mathrm{T}$ $\mathrm{HE}$ development of long coils for $\mathrm{Nb}_{3} \mathrm{Sn}$ accelerator magnets has achieved significant milestones in the past few years. The LARP (LHC Accelerator Research Program) reached $90 \%$ of the short sample limit (s.s.l.) with LRS01 [1] a Long Racetrack magnet (LR) made of two 3.6-m long racetrack coils supported by an aluminum-shell-based structure preloaded using bladders and keys; and $96 \%$ of the s.s.l. with LRS02 [2], a reassembly of the LRS01 coils using a segmented aluminum-shell-based structure. At FNAL LM01, a Long Mirror magnet (LM) with a 2-m long cos-theta coil, reached the s.s.l. [3]; and LM02, with a 3.7-m long coil, although limited by conductor instability, eventually reached

Manuscript received 19 August 2008. This work was supported in part by the U.S. Department of Energy.

G. Ambrosio, N. Andreev, E. Barzi, R. Bossert, G. Chlachidize, V.V. Kashikhin, M. Lamm, F. Nobrega, I. Novitsky, D. Turrioni, G. Whitson, A.V. Zlobin are with Fermilab, Batavia IL 60510 USA (G. Ambrosio phone: +1 630-840-2297; e-mail: giorgioa@ fnal.gov).

M. Anerella, A. Ghosh, G. Jochen, P. Kovach, J. Muratore, S. Peggs, J. Schmalzle, P. Wanderer are with BNL, Upton NY 11973, USA.

S. Caspi, D. Dietderich, H. Felice, P. Ferracin, R. Hafalia, R. Hannaford, A. Lietzke, S. Prestemon, G.L. Sabbi, are with LBNL, Berkeley CA 94720, USA. DOE Contract No. DE-AC02-05CH11231

A. McInturff, is with LBNL and Texas A\&M University, College Station, Texas 77843, USA
87\% of the s.s.l. [4] (without taking into account the temperature increase) when heaters were used to increase the temperature of the outer layer.

The performances of these magnets show that several challenges for the fabrication of $\mathrm{Nb}_{3} \mathrm{Sn}$ coils [5] in the 2-4 $\mathrm{m}$ length range have been overcome, although a few remain.

The most significant challenge that remains to be faced is the heat treatment of long accelerator-quality $\mathrm{Nb}_{3} \mathrm{Sn}$ coils. The Long Quadrupole (LQ) R\&D is addressing this challenge aiming at a gradient equal to or higher than $200 \mathrm{~T} / \mathrm{m}$ in a 90 $\mathrm{mm}$ aperture with $3.3-\mathrm{m} \mathrm{Nb} \mathrm{Nn}_{3}$ coils.

\section{LONG QUADRUPOLE DESIGN AND PLANS}

A preliminary design of the Long Quadrupole, with three options for the support structure, was presented in [6]. Further analysis and optimization have generated a new design of the long aluminum-shell-based structure [7]. A model of the new design is presented in Fig 1.

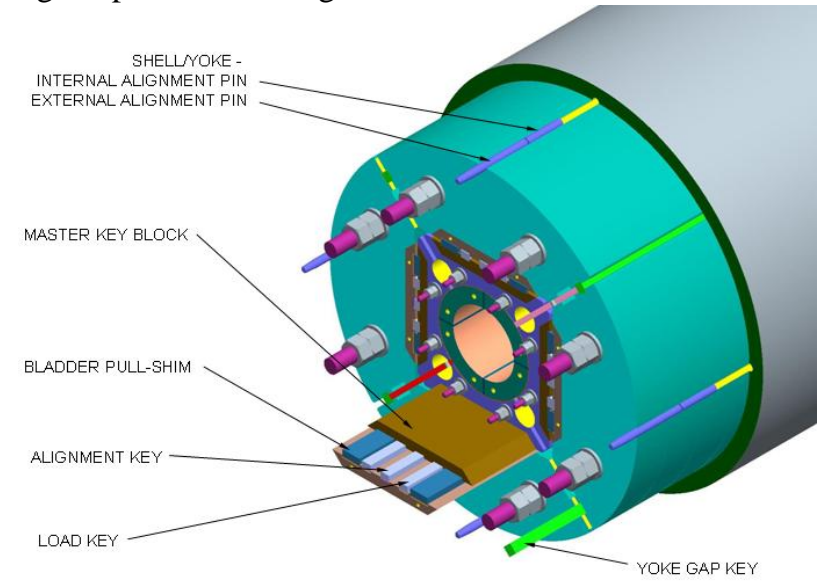

Fig. 1. Solid model of the LQ with aluminum-shell-based structure (LQS).

The main features of this new design (LQS) are: the aluminum shell is made of four segments, the rods for end preload are closer to the coils, the cross-section design has been optimized to assure more uniform pre-load of inner and outer layer, masters are used to facilitate keys and bladders insertion. The successful test of LRS02 [2] has shown the feasibility and advantages of a segmented aluminum shell, as planned for the LQS structure.

More details about the LQ design can be found in [8], [9].

This design work and additional feedback from TQ magnet 
tests [10], [11] contributed to the generation of the R\&D plan presented at the LQ Magnet Structure Review [12]. The main features of the plan are: (i) procurement of both shell- and collar-based structures in 2008; (ii) use of the shell-based structure for the first LQ (LQS01); (iii) in case of successful LQS01 test: second assembly of the shell-based structure with new coils (LQS02), and reuse of LQS01 coils with the collarbased structure (LQC01).

The advantages of this plan are: (i) a large probability of success within 2009 by developing both structures, which provide backup and options; (ii) it builds a large and unique set of expertise and experimental data for the design of the structure for the LHC phase-II upgrade prototype (and for any other future use of $\mathrm{Nb}_{3} \mathrm{Sn}$ in accelerator magnets).

\section{COIL FABRICATION}

\section{A. The Challenge}

The challenge of performing the heat treatment of long accelerator-quality $\mathrm{Nb}_{3} \mathrm{Sn}$ coils is due to the requirement of tight coil confinement in order to assure, for magnet field quality: precise location of each turn, uniformity along the whole length, and reproducibility from coil to coil. This requirement is in conflict with the need to accommodate the coil volume expansion due to the $\mathrm{Nb}_{3} \mathrm{Sn}$ phase formation, and the different thermal expansion and contraction of the materials involved with the heat treatment: conductor, coil pole (sometime referred to as island), and reaction fixture.

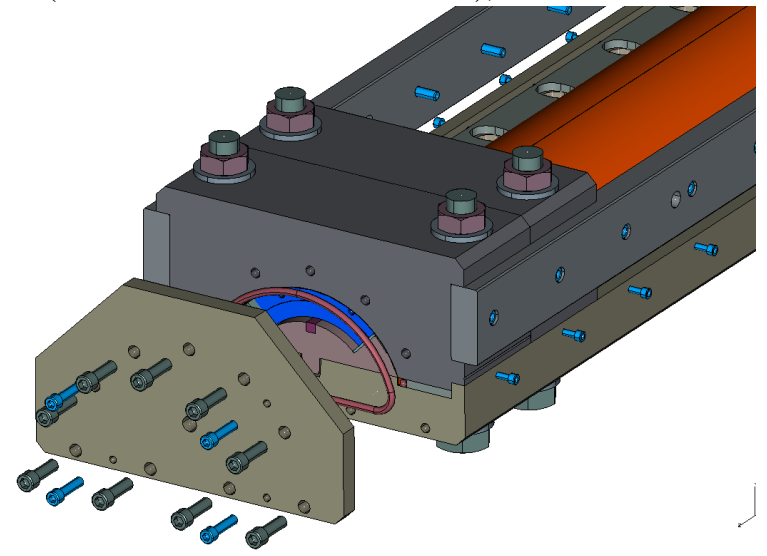

Fig. 2. Model of the reaction fixture used for the first LQ Nb3Sn practice coil showing: end plate, base plate, $76-\mathrm{mm}$ long mandrel blocks, $0.25-\mathrm{mm}$ thick stainless steel liner, 76-mm long block defining the coil OD, side bars, end plates, and gaskets made of thin-wall stainless or copper tubes.

\section{B. The Reaction Fixture and Procedure}

The LQ reaction tooling is based on the TQ double cavity mold, with some significant differences: (i) the LQ tooling is designed to perform the reaction and impregnation of one coil at a time (assuring better coil symmetry); (ii) the coil inner surface and mid-planes are supported and confined by precision wire-cut blocks. The main components of the reaction fixture used for the heat treatment of the first LQ $\mathrm{Nb}_{3} \mathrm{Sn}$ coil are shown in Fig 2. They consist of: a 3.4-m long base plate, $76-\mathrm{mm}$ long mandrel blocks, a $0.25-\mathrm{mm}$ thick stainless steel liner, 76-mm long block setting the coil outer diameter, side bars, end plates, and gaskets made of thin-wall stainless or copper tubes. The closed cavity mold defines the coil size precisely, ultimately assuring the magnet field quality.

Fig 3 shows the material added to the coil in preparation for heat treatment, at the beginning of the LQ R\&D: one 250-um ceramic cloth on the inner surface, two 250-um ceramic clothes (or S2-glass clothes providing the same total thickness) on the coil outer surface, and a 125-um stainless steel shim on each coil mid-planes. The fixture cavity is closed using 19-mm size stainless steel bolts with a nominal torque of $217 \mathrm{Nm}$ (160 ft-lbs). When the cavity is closed the force is reacted by the fixture. The maximum applicable pressure on the coil is $40 \mathrm{MPa}$.

During reaction, the oven temperature is monitored continuously by thermocouples placed around and within the reaction fixture. The reaction cycle was tested on strand and cable samples, and TQ magnets using the same conductor (RRP $54 / 61$ by OST). The steps of the LQ heat treatment cycle are:

- ramp from $20^{\circ} \mathrm{C}$ to $210^{\circ} \mathrm{C}$ at $25^{\circ} \mathrm{C} / \mathrm{hr}$;

- hold at $210^{\circ} \mathrm{C}$ for $72 \mathrm{hr}$

- ramp from $210^{\circ} \mathrm{C}$ to $400^{\circ} \mathrm{C}$ at $25^{\circ} \mathrm{C} / \mathrm{hr}$;

- hold at $400^{\circ} \mathrm{C}$ for $48 \mathrm{hr}$

- ramp from $400^{\circ} \mathrm{C}$ to $640^{\circ} \mathrm{C}$ at $50^{\circ} \mathrm{C} / \mathrm{hr}$;

- hold at $640^{\circ} \mathrm{C}$ for $48 \mathrm{hr}$

- ramp from $640^{\circ} \mathrm{C}$ to $20^{\circ} \mathrm{C}$ in $48 \mathrm{hr}$;

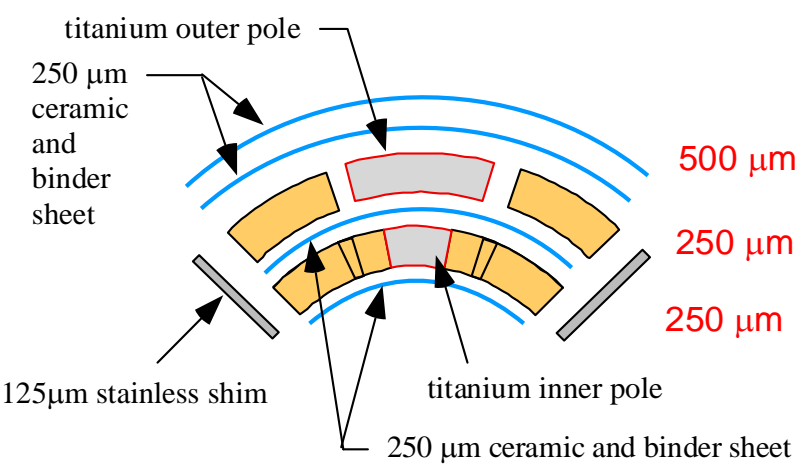

Fig. 3. LQ coil cross-section during heat treatment showing: cable stacks (made of cables, cable insulation, and wedges), titanium pole parts, ceramic clothes, and stainless steel shims on the coil mid-planes.

Gas tight reaction furnaces are used at Fermilab and BNL with $99.99 \%$ pure argon gas to perform the coil heat treatment. Two gas supplies are used, one for the furnace volume with a flow rate of $24 \mathrm{~L} / \mathrm{min}(50 \mathrm{SCFH})$ and one for the reaction tooling using a gas flow rate of $12 \mathrm{~L} / \mathrm{min}(25 \mathrm{SCFH})$. These flow rates maintain a small positive pressure within the reaction fixture and the furnace. Exhaust gas is passed through a filter to capture oil from the cable that was used for strand manufacturing and palmitic acid, a binder for the cable insulation. Temperature uniformity within the furnace volume can be maintained within $\pm 3^{\circ} \mathrm{C}$ at all three temperature plateaus.

\section{First $\mathrm{Nb}_{3} \mathrm{Sn}$ Practice Coil}

The fixture shown in Fig 2 presented a bowing of $34 \mathrm{~mm}$ after the heat treatment of the first $\mathrm{Nb}_{3} \mathrm{Sn}$ practice coil (LQ02). The bowing caused the fixture to touch a flat surface only at the ends when oriented as in Fig 2. The fixture became flat as 
soon as the bolts were released. The bowing was due to the reaction of the base plate to a longitudinal force applied on a different plane (causing a moment) by the coil and/or the rest of the fixture. Three possible causes were identified and evaluated:

- The coil expansion due to the $\mathrm{Nb}_{3} \mathrm{Sn}$ formation: if the cross-section of the fixture cavity is too tight the coil may have a significant longitudinal growth [13]. If friction prevents this growth the coil applies a longitudinal force to the fixture.

- Non-uniform longitudinal expansion/contraction of the reaction fixture during heat treatment: if the blocks of the fixture do not expand and contract as much as the plate, they may cause a longitudinal force.

- Different thermal expansion/contraction of the coil pole and of the fixture: the pole is made of Ti-6Al-4V alloy, the reaction fixture of 304 stainless steel, which have significantly different thermal expansion in the range $20^{\circ}$ to $640^{\circ} \mathrm{C}$. The coil cross-section grows during the $\mathrm{Nb}_{3} \mathrm{Sn}$ formation, increasing the friction between the pole and the fixture. The pole applies a longitudinal force if it cannot slide with respect to the fixture during cooldown.

An analytical model of the fixture, used to compute the force necessary to cause the bending of the base plate $(\sim 250$ $\mathrm{kN}$ ), disproved the first hypothesis because the maximum force that the coil can apply is orders of magnitude smaller. All parts of the reaction fixture were subjected to a pre heat treatment $\left(125\right.$ hours at $\left.650^{\circ} \mathrm{C}\right)$ in order to avoid any change during coil heat treatments. Measurements of parts after the heat treatment of LQ02 showed no changes. In addition to this, the location and amount of gaps among the blocks of the fixture disproved the second hypothesis. The difference between the expansion of the fixture and the pole is $18.6 \mathrm{~mm}$. Therefore each pole tip should slide by $9.3 \mathrm{~mm}$, with respect to the fixture, during the final cooldown. If slightly less than half this displacement is prevented by friction, the resulting force could cause the measured bowing. Ceramic or S2-glass cloth can cause high friction between fixture, pole, and coil. Therefore it was decided to change the materials surrounding the coil during the heat treatment, and to adopt the scheme shown in Fig 4.

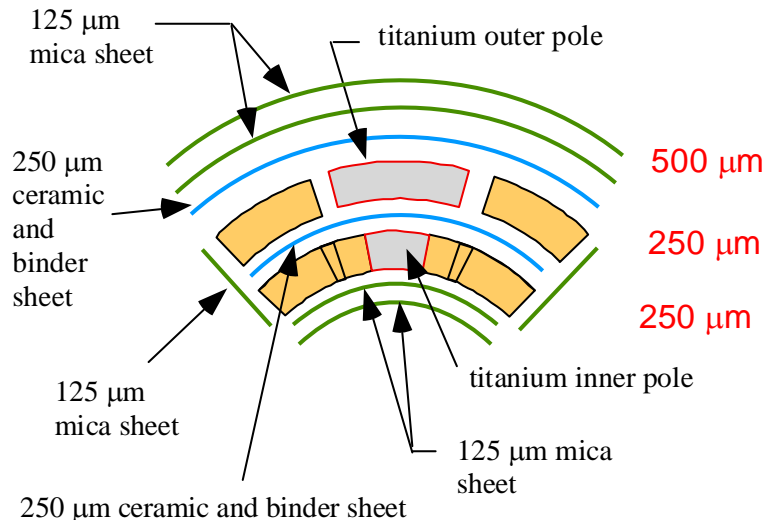

Fig. 4. New LQ coil cross-section during heat treatment showing: cable stacks, titanium pole parts, ceramic clothes, and mica layers.

In this new configuration mica sheets cover all contact surfaces between the coil package (conductor and pole) and the fixture, assuring good sliding. Another plate, as long as the whole fixture, was added on the top of the blocks in order to increase the rigidity of the fixture and making it more symmetric, in order to prevent any other possible cause of bending (Fig. 5).

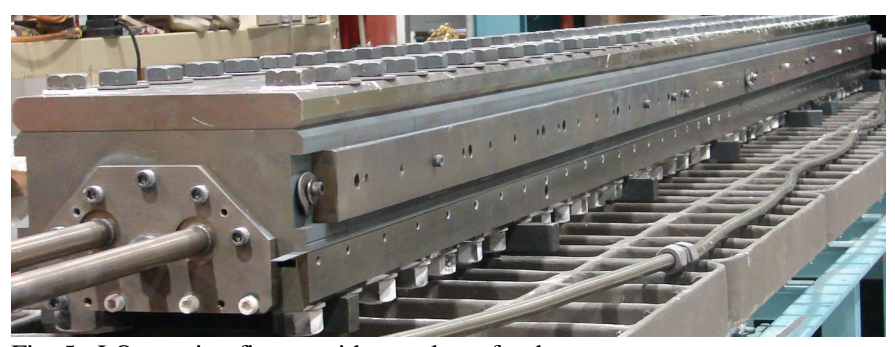

Fig. 5. LQ reaction fixture with top plate after heat treatment.

\section{Second $\mathrm{Nb}_{3} \mathrm{Sn}$ Practice Coil}

The second $\mathrm{Nb}_{3} \mathrm{Sn}$ Practice Coil (LQ03), reacted with the modifications described previously, didn't show any bowing. Nonetheless other problems were found during inspection after the heat treatment. The inner-layer pole was shorter by $4.3 \mathrm{~mm}$, and the outer-layer pole by $0.3 \mathrm{~mm}$. In addition, the inner-layer pole had approximately $550 \mathrm{Kg}$ of compressive longitudinal load (measured when the central pole part was removed). After the central pole part was removed, the inner layer coil shrunk by additional $0.5 \mathrm{~mm}$. The outer pole, however, did not have any longitudinal compression. Both inner- and outer-layer coil ends showed a higher compaction after the heat treatment, resulting in a shortening of $2 \mathrm{~mm}$ (inner layer coil) and $1.2 \mathrm{~mm}$ (outer layer coil).

Normally, the inner layer pole pieces would not be removed after reaction, as they were not removed on the TQ coils. Therefore it is not known whether tension on the inner layer existed in the TQ coils. Presently there are no data about possible TQ coil length changes after the reaction. The high tension on the inner layer of LQ03 was discovered when the outer poles were removed for observation of the inner layer, and the inner layer began to spring upward due to the high column loading on the inner pole pieces.

As a result of these observations, the LQ coil production was stopped for about six weeks. Check of material properties, modeling, measurements and tests took place at BNL, FNAL and LBNL in order to understand the issue before proceeding with the next LQ coil reaction. The most relevant results were:

- Titanium pole creep: the Ti-6Al-4V alloy can be subject to significant creep during the 48 -hrs plateau at $640^{\circ} \mathrm{C}$ if small pressure is applied [14].

- Winding tension: the winding tension $(16 \mathrm{Kg})$ generates a force at each pole tip trying to shorten the pole. The central pole parts of two LQ coils were removed after curing the ceramic binder, and the coils shrunk by $2.5-3$ $\mathrm{mm}$. The shrinkage occurred slowly during a few days because the binder holds some tension.

- Cable shrinkage during heat treatment: each LQ cable undergoes a partial annealing ( 2 hours at $200^{\circ} \mathrm{C}$ ) during fabrication. However this is not sufficient to prevent further shrinkage at the beginning of the heat treatment. An LQ cable, extracted from the oven when the standard LQ heat treatment was stopped after $36 \mathrm{hrs}$ at $400^{\circ} \mathrm{C}$, showed shrinkage by $0.39 \%$ at room temperature (RT). 
- Coil thermal contraction from $640^{\circ}$ to $20^{\circ} \mathrm{C}$ : the coil thermal contraction during the cooldown was computed by comparing coil and gap dimensions, before and after heat treatment, in coils of the TQ01-series (with aluminum bronze pole and gaps), the LR and the LM. The most precise result was obtained by the analysis of LR coils showing that the thermal contraction was larger than $8.3 \mathrm{~mm} / \mathrm{m}$. The thermal contraction of Ti-6Al-4V in the same temperature range is $6.1-6.5 \mathrm{~mm} / \mathrm{m}$ (depending on sources) [14], [15].

- Different azimuthal load: Tests with pressure sensitive films revealed a $380 \mu \mathrm{m}$ "step" between the inner and outer layer on both midplanes (the inner layer being "shorter" in azimuthal direction) after curing. This "step" can cause different azimuthal loads during reaction.

Based on these observations, the present understanding of what happened during LQ03 reaction is:

1. At the beginning of the heat treatment (up to the $400^{\circ} \mathrm{C}$ plateau) the coil contraction increased the pressure on the pole tips caused by the winding tension.

2. When the $640^{\circ} \mathrm{C}$ plateau was reached the pole tips were still under pressure because the previously mentioned factors overcame the small thermal expansion of the pole.

3. During the $640^{\circ} \mathrm{C}$ plateau the pole shrunk under this load because of creep.

4. During the cooldown from $640^{\circ}$ to $20^{\circ} \mathrm{C}$ the coil thermal contraction, higher than the pole thermal contraction, caused the longitudinal force.

The outer layer showed negligible pole shrinkage and no coil tension. This different behavior may be explained by the larger azimuthal pressure during heat treatment.

Because of these findings and understanding the following modifications were introduced in the LQ coil fabrication procedures:

- Winding and curing: the coils are wound and cured with gaps among pole parts (nine gaps of $0.6 \mathrm{~mm}$ ) following the procedures used for the TQ01 coil series. The winding tension is reacted by hooks connecting both pole tips to the ends of the winding mandrel. The tension is removed after the final curing by slowly releasing the hook on the return end. The total gap should be reduced by half $(\sim 3$ $\mathrm{mm}$ ) after tension is removed.

- Inner and outer layer curing: presently there is not sufficient understanding of the causes of the mid-plane step to implement modifications to the LQ fabrication process. However a reduction of the width of the outer layer pole parts by $0.15 \mathrm{~mm}$ (decided after measurement of LQ02 cross sections) may reduce it.

- Heat treatment: the gaps should accommodate the coil shrinkage during heat treatment, avoiding the pole creep at $640^{\circ} \mathrm{C}$ and the coil tension after cooldown to $20^{\circ} \mathrm{C}$.

Two LQ coils, which were wound and cure without gaps, have been adapted to this new procedure by removing and shortening the central pole parts. Inspection of these coils after heat treatment is going to provide additional data for the possible fine tuning of the gap dimensions.

On a longer term several cable heat treatment tests are planned in order to check the preliminary measurement performed for this analysis, and to improve the present understanding. A finite element analysis of the reaction process is also planned when adequate understanding of the related material properties will be achieved. An analysis of the curing process has started in order to avoid steps on the coil mid-plane.

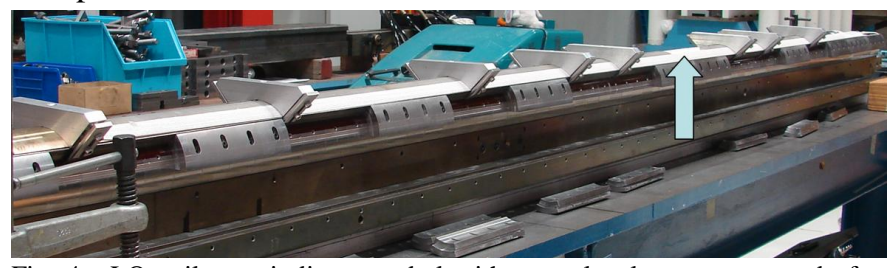

Fig. 4. LQ coil on winding mandrel with central pole parts removed after curing (the arrow points to the missing pole parts).

\section{CONCLUSION}

The LQ R\&D has started the fabrication of the long $\mathrm{Nb}_{3} \mathrm{Sn}$ coils after finalizing the design of the support structure and plans. Some problems, found during inspection of the first practice coils, caused delays but also an improved understanding of the heat treatment process. After some modifications the LQ coil fabrication was restarted aiming at testing the first LQ in summer 2009.

\section{ACKNOWLEDGMENT}

The authors thank S. Sgobba (CERN) for useful discussion and information about Ti-6Al-4V properties, and D. Tommasini (CERN) for useful discussion about coil preparation for heat treatment.

\section{REFERENCES}

[1] P. Wanderer, et al., "Construction and Test of $3.6 \mathrm{~m} \mathrm{Nb}_{3} \mathrm{Sn}$ Racetrack Coils for LARP”, IEEE Trans. on App. Supercond., vol. 18, no. 2, pp. 171 - 174, June 2008

[2] J.F. Muratore, et al., "Test Results of LARP 3.6 m Nb3Sn Racetrack Coils Supported by Full-Length and Segmented Shell Structures" this conference, 5LX02

[3] F. Nobrega, et al., " $\mathrm{Nb}_{3} \mathrm{Sn}$ Accelerator Magnet Technology Scale-up using Cos-theta Dipole Coils", IEEE Trans. on App. Supercond., vol. 18, no. 2 , pp. 273 - 276 , June 2008

[4] G. Chlachidze, et al., "Quench performance of a 4-m long Nb3Sn costheta dipole coil" this conference, 5LX03

[5] G. Ambrosio, et al., "Design of $\mathrm{Nb}_{3} \mathrm{Sn}$ coils for LARP long magnets", IEEE Trans. on App. Supercond., vol. 17, no. 2, pp. 1035-1038, 2007

[6] G. Ambrosio, et al., "LARP Long Nb3Sn Quadrupole Design", IEEE Trans. on App. Supercond., vol. 18, no. 2, pp. 268 - 272, June 2008

[7] P. Ferracin, et al., "Fabrication and Test of a $3.7 \mathrm{~m}$ Long Support Structure for the LARP Nb3Sn Quadrupole Magnet LQS01", this conference, 2LPA03

[8] G. Ambrosio, et al., "Long Quadrupole Design Report", LARP report available on line at:

https://plone.uslarp.org/MagnetRD/longquad/LQ_DR.pdf

[9] H. Felice, et al., "Instrumentation and Quench Protection for LARP Nb3Sn magnets", this conference, 3LPH11

[10] S. Caspi, et al., "Test Results of LARP Nb3Sn Quadrupole Magnets Using a Shell-based Support Structure (TQS)", this conference 5LX04

[11] R.C. Bossert, et al., "Fabrication and Test of LARP Technological Quadrupole Models of TQC Series", this conference 5LX05

[12] LQMSR presentations available on line at: http://larpdocs.fnal.gov/LARP-public/DocDB/ShowDocument?docid=690

[13] D.R. Chichili, et al., "Fabrication of the Shell-Type Nb3Sn Dipole Magnet for Fermilab", IEEE Trans. on App. Supercond., vol. 11, no. 1, pp. 2160 - 2163, March 2001

[14] Metals Handbook 8th Edition

[15] MatWeb database available on line at: www.matweb.com 